\title{
Estigma e discriminação vividos na escola por crianças e jovens órfãos por Aids*
}

\author{
Eliana Miura Zucchi** \\ Claudia Renata dos Santos Barros \\ Vera Silvia Facciolla Paiva \\ Ivan França Junior \\ Universdidade de São Paulo
}

Correspondência:

Ivan França Junior

Faculdade de Saúde Pública/USP

Av. Dr. Arnaldo, 715 - sala 218

01246-904 - São Paulo/SP

E-mail: ifjunior@usp.br

\footnotetext{
* Artigo baseado na dissertação de mestrado de Eliana M. Zucchi, apresentada ao Programa de Pós-graduação em Saúde Pública da Faculdade de Saúde Pública, Universidade de São Paulo, em 2008. Fundação de Amparo à Pesquisa do Estado de São Paulo (Fapesp).

** Agradecemos à professora Marilene Proença, do Instituto de Psicologia da Universidade de São Paulo, pelas críticas e sugestões na análise dos resultados. Às professoras Daniela Riva Knauth, da Faculdade de Medicina, e Paula Sandrine Machado, do Instituto de Psicologia da Universidade Federal do Rio Grande do Sul, pelas sugestões na discussão do texto final no âmbito do I Seminário de Escrita Científica em Pesquisas Qualitativas em Saúde Pública, realizado na Faculdade de Saúde Pública da USP em 2009.
}

\section{Resumo}

A restrição de direitos humanos é uma das características mais marcantes da epidemia da Aids. Crianças e jovens infectados ou afetados pela Aids são particularmente vulneráveis a sofrer estigma em ambientes educacionais. 0 objetivo deste artigo foi analisar episódios de estigma e discriminação relacionados ao HIV/Aids na escola.

Integradas a um estudo de base populacional, foram analisadas sete entrevistas em profundidade com coordenadores pedagógicos de seis escolas públicas e privadas, de ensino infantil e fundamental, na cidade de São Paulo.

A maioria dos episódios de estigma vividos por crianças e jovens no âmbito escolar ocorreu em circunstâncias de namoro/ sexualidade, conflito com colegas, dificuldade de aprendizagem, revelação da orfandade por Aids, interação entre professores e alunos com HIV, sendo as causas mais frequentemente atribuídas: ter HIV, ser proveniente de "família desestruturada", desigualdade nos papéis de gênero, idade e classe social. Homofobia e racismo foram indicados como reforçadores do estigma. Foram descritas respostas institucionais ao estigma da Aids e práticas de atividades de prevenção às DST/Aids.

Os episódios indicam o quanto o estigma e a discriminação relacionados ao HIV/Aids podem aprofundar uma desigualdade social já instalada no âmbito da educação, constituindo obstáculos ao direito à educação, à convivência familiar, ao lazer, à privacidade, ao sigilo/confidencialidade e à vida afetiva dos jovens. Por outro lado, tais episódios também expressam a ausência de programas de prevenção nas escolas visitadas e a dificuldade de abordar outras modalidades de estigma (tais como racismo e estigma da pobreza).

\section{Palavras-chave}

Estigma da Aids - Direito à educação - Órfãos por Aids. 


\title{
Stigma and discrimination at school experienced by children and youngsters orphaned by AIDS*
}

\author{
Eliana Miura Zucchi* \\ Claudia Renata dos Santos Barros \\ Vera Silvia Facciolla Paiva \\ Ivan França Junior \\ Universidade de São Paulo
}

\author{
Contact: \\ Ivan França Junior \\ Faculdade de Saúde Pública/USP \\ Av. Dr. Arnaldo, 715 - sala 218 \\ 01246-904 - São Paulo/SP \\ E-mail: ifjunior@usp.br
}

\begin{abstract}
The restriction of human rights is one of the most poignant features of the AIDS epidemics. Children and youngsters infected or otherwise affected by AIDS are particularly vulnerable to stigma in educational environments. The purpose of this article is to analyze episodes of stigma and discrimination related to HIV/AIDS at school. Integrated to a demographic study, an indepth analysis was made of seven interviews conducted with pedagogical coordinators from six public and private schools of early childhood and fundamental education in the city of São Paulo. The majority of episodes of stigma experienced by children and youngsters within schools took place in circumstances of dating/sexuality, conflict with schoolmates, learning difficulties, disclosure of orphanhood by AIDS, and interaction between teachers and pupils with HIV, with the most frequently mentioned causes being: being HIV-positive, coming from a "dysfunctional family", and inequality in gender roles, age, and social class. Homophobia and racism were pointed out as stigma reinforcements. Descriptions were made of institutional responses to the AIDS stigma and of practices of prevention against STDs/AIDS. The episodes indicate the extent to which the stigma and discrimination related to HIV/AIDS can aggravate the social inequality already present within the sphere of education, obstructing the youngsters' rights to education, to family life, to leisure, to privacy, to secrecy/confidentiality, and to a love life. Such episodes also reveal the lack of prevention programs in the schools visited, and the difficulty of dealing with other forms of stigma (such as racism and the stigma of poverty).
\end{abstract}

\section{Keywords}

AIDS stigma - Right to Education - Orphans of AIDS. 
Uma das características mais marcantes da epidemia da Aids, além dos aspectos clínicos dessa doença infecto-transmissível, foram a diversidade e intensidade de respostas sociais produzidas pela epidemia. Desde meados da década de 1980, o estigma da Aids é assinalado como a mais negativa e prejudicial destas respostas (Mann; Tarantola; Netter, 1992). Apoiados na definição de Erving Goffman (1978), compreendemos o estigma como um processo socialmente construído de desvalorização do indivíduo, que passa a ser portador de uma identidade deteriorada.

As associações mobilizadas entre Aids e morte, punição e desvio, foram constituindo diversos estereótipos de explicações imprecisas sobre a epidemia, fomentando respostas de estigmatização (Parker; Aggleton, 2001). Tais respostas geralmente levam a ações ou omissões que são danosas ou que negligenciam o acesso a determinados serviços, bens e posições sociais, caracterizando, assim, a discriminação, definida como: "na ausência de justificativa objetiva, o sujeito sofre uma distinção que resulta em tratamento injusto direcionado a um grupo específıco" (Maluwa; Aggleton; Parker, 2002, p. 6).

Aids, infância e educação

Com relação às primeiras crianças infectadas e afetadas pela Aids, o estigma e a discriminação relacionados ao HIV/Aids no âmbito escolar tiveram como expressão a ambiguidade de mensagens sobre "vítimas inocentes" (ou seja, alunos soropositivos) e, simultaneamente, o medo da comunidade escolar em recebê-los e aceitá-los na escola (Parker; Aggleton, 2001). Dessa forma, não só o direito à educação pode ser restrito nas escolas, como também outros direitos (convivência familiar, lazer, privacidade, sigilo/confidencialidade) e esferas da vida (namoro, sexualidade).

No Brasil, o caso de maior destaque ocorreu em 1992, em São Paulo, quando Sheila, uma menina de 6 anos, teve sua matrícula recusada por ter HIV (ABIA, 1993). Situações similares que já haviam ocorrido em outras escolas e a grande repercussão deste caso possibilitaram que esta questão, inicialmente restrita ao âmbito escolar, fosse debatida publicamente. Um dos desdobramentos foi a criação da Portaria Interministerial ${ }^{1}$ - Ministérios da Saúde e Educação - que garante o acesso à escola e a preservação do sigilo da condição sorológica de crianças com HIV (ABIA, 1993).

Nessa mesma Portaria, atividades de prevenção às DST/Aids tornam-se metas a serem implementadas nas escolas:

Art. $2^{\circ}$ - Recomendar a implantação, onde não exista, e a manutenção e ampliação, onde já se executa, de projeto educativo, enfatizando os aspectos de transmissão e prevenção da infecção pelo HIV e Aids, dirigido a professores, pais, alunos, funcionários e dirigentes das redes oficial e privada de ensino de todos os níveis, na forma do anexo. [...] $2^{\circ}$ - Os conteúdos programáticos do projeto educativo deverão estar em consonância com as diretrizes do Programa Nacional de Controle das Doenças Sexualmente Transmissíveis e AIDS do Ministério da Saúde. (Portaria Interministerial 769, de 29/05/1992)

Contudo, observa-se que, historicamente, os programas de prevenção às DST/Aids nas escolas ${ }^{2,3}$, foram formulados tendo como destinatário o "polo negativo" da epidemia de Aids, ou seja, jovens, em princípio, soronegativos para o HIV e que devem ser protegidos da infecção. Tais programas não incluem em suas diretrizes jovens que, independentemente de sua sorologia, convivem com HIV/Aids.

\section{Direitos humanos de crianças e jovens convivendo com HIV/Aids}

Decorridos mais de 25 anos do início da epidemia e com o aumento da expectativa de vida das pessoas vivendo com HIV (em

1. Portaria Interministerial 769 , de $29 / 05 / 1992$

2. Programa Escola Promotora de Saúde - Secretaria Municipal de Educação, São Paulo (SP).

3. Projeto Prevenção Também se Ensina - Secretaria da Educação do Estado de São Paulo. 
função do acesso à terapia antirretroviral), há atualmente um segmento ainda pouco conhecido: crianças e jovens que ficaram órfãos em decorrência da Aids.

No período de 1980 e 2008 na cidade de São Paulo (SP) foram registrados 1.673 casos de Aids entre crianças e adolescentes, dos quais 382 (23\%) possuíam idade entre 5 e 9 anos, 128 (8\%) entre 10 e 12 anos e 1.163 (69\%) entre 13 e 19 anos (Boletim Epidemiológico de Aids, HIV/DST e Hepatites B e C do Município de São Paulo, 2009).

Especificamente em relação a crianças e jovens órfãos por Aids, um estudo de base populacional realizado em São Paulo ${ }^{4}$ identificou 377 (18\%) crianças e adolescentes de 7 a 18 anos de uma amostra probabilística de 2.071 pessoas maiores de 18 anos falecidas por Aids entre 2000 e 2004. Quatorze (5,6\%) dessas crianças/adolescentes eram soropositivos para o HIV.

Ainda não se tem conhecimento do número exato de órfãos por Aids no Brasil, sendo necessário que as estimativas baseadas em modelos matemáticos sejam referidas com cautela devido à existência de viés metodológico (França-Junior; Doring; Stella, 2006).

Na experiência da orfandade por Aids, além do desamparo da criança/jovem, decorrente da perda de um dos pais, o estigma e a discriminação relacionados ao HIV/Aids podem ser um elemento crítico na promoção e proteção de direitos em vários contextos (Doring, 2005), inclusive na educação.

Em estudo realizado em Porto Alegre (RS) sobre crianças e jovens que ficaram órfãos em decorrência da Aids entre 1998 e 2001, foram constatadas dificuldades na escolarização da população estudada: 13\% das crianças órfãs em idade escolar estão fora da escola (comparado a taxa de 3\% da região Sul $)^{5} ; 62 \%$ apresentam defasagem série/idade (a defasagem escolar no Sul oscila entre $4,1 \%$ e 57,3\%) ${ }^{6}$, 65\% relataram dificuldades de aprendizagem, um quarto apresentou evasão escolar, e 53\% apresentaram ao menos uma reprovação. Dentre as razões alegadas para não frequentar a escola, foram registradas: perda de vontade de estudar após a morte dos pais, gravidez/maternidade na adolescência, interrupção dos estudos para trabalhar e dificuldade de conseguir vaga (Doring, 2005).

Ao investigar a percepção de professores acerca de alunos com HIV, Krokoscz (2005) observou que transmissão do vírus, aprendizagem e inclusão foram os temas mais recorrentes em situações de conflito envolvendo tais alunos em escolas públicas e privadas na Região Metropolitana de São Paulo. Em pesquisa na África do Sul, professores de ensino fundamental identificaram como importantes necessidades psicossociais de alunos órfãos por Aids o desejo de segurança, aceitação, lidar com estresse e medo e disponibilidade de serviços de suporte psicossocial. Depressão, tristeza e estigmatização foram percebidas como as principais influências sobre o comportamento desses alunos (Witt; Lessing, 2005).

Há importantes perguntas em relação à representação de educadores sobre a vida escolar de crianças e jovens órfãos por Aids: acontecimentos como, por exemplo, a perda dos pais, foram objeto de atenção da escola? Os direitos fundamentais desses alunos (liberdade, respeito, dignidade, educação, cultura, esporte e lazer), previstos no Estatuto da Criança e do Adolescente, estão assegurados? Estão livres de estigma e discriminação? Caso não estejam, há ações prescritas no âmbito institucional? Assim, não sabemos se ou o quanto o estigma da Aids repercutiu nessa esfera da vida, bem como as reações individuais, coletivas ou institucionais adiante da discriminação.

0 objetivo do presente estudo foi analisar episódios de estigma e discriminação vividos por crianças e jovens órfãos por Aids na escola e as respostas institucionais ao estigma. 4. "Estigma e discriminação relacionados ao HIV/AIDS: impactos da epidemia
em crianças e jovens na cidade de São Paulo". Faculdade de Saúde Pública,
Universidade de São Paulo [Relatório de pesquisa].
5. IBGE - Pesquisa Nacional por Amostra de Domicílios 2001. Disponível em:
<http://www.ibge.gov.br/home/estatistica/populacao/trabalhoerendimento/
pnad2001/sintese2001.pdf>. Acesso em: 27 abr. 2007 .
6. Na faixa compreendida entre 7 a 14 anos, a defasagem escolar no Sul oscila entre $4,1 \%$ e $57,3 \%$.. 


\section{Procedimentos metodológicos}

Integrado a um estudo de base populacional $^{7}$, foram realizadas sete entrevistas em profundidade com um diretor e seis coordenadores pedagógicos de seis escolas públicas e privadas, de ensino infantil e fundamental, das regiões Norte, Leste e Oeste da cidade de São Paulo, epicentro da epidemia de Aids no Brasil.

0 critério para escolha das escolas participantes foi a indicação dos serviços especializados em DST/Aids participantes da pesquisa, que buscaram identificar escolas localizadas na mesma região destes serviços e que, possivelmente, tivessem tido alguma interlocução com estes. Posteriormente, a equipe de pesquisa contatou as escolas, e foi feita uma reunião com diretores, assistentes de direção e coordenadores pedagógicos para apresentá-los à pesquisa e convidá-los a participar.

Foi solicitado aos participantes que recordassem ou imaginassem o cotidiano escolar de alunos órfãos por Aids em seu local de trabalho e o descrevessem a partir de perguntas que expressassem cinco eixos de investigação do estigma e discriminação relacionados ao HIV/ Aids: 1) simbolismos da Aids; 2) restrição de horizontes ${ }^{8}$; 3) sinergia de pragas $^{9}$; 4) conhecimentos que podem ajudar a lidar com o estigma; e 5) organização social e institucionalização do estigma. A fim de obter maior diversidade nos relatos, foram estabelecidos alguns contrapontos: soropositvidade, tipo de orfandade (pai, mãe ou ambos), institucionalização, raça/etnia, gênero e idade.

0 estudo maior, ao qual se integra o presente trabalho, foi aprovado pelos Comitês de Ética em Pesquisa da Faculdade de Saúde Pública, do Centro de Referência e Treinamento em DST/Aids e da Secretaria Municipal de Saúde de São Paulo.

\section{Análise dos resultados}

Em geral, os entrevistados negaram a ocorrência de estigma da Aids na escola. Con- tudo, identificamos episódios em que alunos órfãos, bem como suas famílias, são colocados em condição de desvantagem em várias esferas da vida, inclusive quanto ao futuro. Apresentamos a seguir as circunstâncias em que ocorreram os episódios de estigma, suas respectivas causas, atribuídas pelos entrevistados ${ }^{10}$, e eventuais respostas à discriminação.

\section{Namoro e sexualidade como “problemas"}

Situações envolvendo restrição do namoro ou experiência da sexualidade entre adolescentes foram descritas como problemáticas por se tratar de alunos órfãos por Aids, sendo os principais motivadores a soropositividade, a desigualdade dos papéis de gênero, raça e classe social.

A vida afetiva de jovens órfãos com HIV sofreu interferência direta da escola, conforme relato abaixo, sobre a atitude de uma educadora com relação ao namoro de um casal de alunos sorodiscordante.

[...] Eles andaram aí namorando, se beijando e tudo mais, e aí um dia ela foi conversar com a orientadora de turma [atendendo ao chamado da orientadora]. [...] Ela disse assim "você conhece o J, você sabe quem é o J., não sabe?”. "Ah, eu sei professora, mas eu gosto dele". E a professora disse pra ela: "Olha, filha, na vida a gente faz escolhas, se você fez a sua... Cada um faz a sua escolha, a gente precisa pensar, ver bem se é o que a gente quer" [...] Eu achei que ela tava dizendo pra menina dispensar o J., dispensar realmente. [...] A razão principal era o medo da Aids [...] porque é um problema,

7. "Estigma e discriminação relacionados ao HIV/AIDS: impactos da epidemia em crianças e jovens na cidade de São Paulo". Pesquisa financiada pela Fapesp, sob coordenação do prof. dr. Ivan França Junior - Faculdade de Saúde Pública - Universidade de São Paulo.

8. Impedimento de realizar planos futuros em decorrência da Aids na vida da pessoa, principalmente do estigma associado à doença (Ayres et al., 2006). 9. Interação entre diferentes fontes de estigma (homossexualidade, uso de drogas etc.), que redundam em um círculo vicioso de estigma e discriminação relacionados ao HIV/Aids (Parker; Aggleton, 2001).

10. Os nomes indicados nas falas são fictícios. 
realmente, a gente fala "não tem perigo, não sei o que lá". Mas a gente pensa: "e se fosse a minha filha?", se tivesse namorando um aidético [...] é uma situação complicada... (Escola de ensino fundamental e médio, zona norte)

Segundo outro depoente, a interferência no namoro de outro casal quase resultou em restrição do direito ao sigilo da condição sorológica:

Uma adolescente muito bonita que tava namorando um menininho lá da escola e eles se beijaram, e a diretora ficou em pânico com a situação quando soube que ele tinha beijado a menina [...], a menina era soropositivo e o menino não [...]. Aí a diretora e a professora entraram em pânico e queriam chamar a família do menino pra falar que a menina era soropositivo [...]. A avó (da menina) tava desesperada. (Escola de ensino infantil, zona oeste)

Outro coordenador acrescentou como a cultura sexista pode afetar negativamente a vida sexual dos meninos:

Menino, eles não põe muita coisa na cabeça, não têm muita [...]. A sociedade é machista. Então, quando ele chegou nos 14 anos, o tio falou "Você tem que transar, não sei o quê, não pode, se não vira marica”... Tem isso no discurso machista, isso. Então ele sabia que ele era HIV positivo. Ele sempre soube. E não teve os cuidados que devia pra não contaminar a parceira etc. e tal. E aí passa pra outras pessoas. (Escola de ensino fundamental, zona oeste)

Segundo uma educadora, os direitos reprodutivos seriam uma esfera da vida dos jovens soropositivos com restrições, conforme relato sobre a recomendação de que tais jovens não deveriam ter filhos naturais:

Eles querem namorar, eles querem ter uma namorada e tudo mais, mas eu não sei se eles pensam em formar uma família. Mas, se pensarem em formar uma família, ter filho, eu acho complicado, não é. Eu acho que poderia até casar e adotar uma criança, por que não? Em vez de fazer uma criança nova, pegar uma criança que tá pronta, que não tem Aids. (Escola de ensino fundamental e médio, zona norte)

No relato de uma coordenadora, não haveria quaisquer restrições vividas por alunos órfãos por Aids na escola, até ser indagada sobre namoro, que passa a ser visto com grande preocupação e associado ao sexo masculino.

Entrevistadora: E se essa criança começasse a namorar? Aos 15 anos começa uma paquerinha aqui na escola. Como é que seria?

Coordenadora:: Nossa senhora! (risos). Socorro, eu vou começar o projeto amanhã, não vou esperar o ano que vem! [...] Nossa, meu Deus, o que que a gente vai fazer? A gente vai orientar essa criança no particular [...] a escola sabe que essa criança tem e então, por consequência, a criança sabe que a escola sabe. E isso nos dá a liberdade de chamá-la e perguntá-la qual a relação dela nesse namoro, se está havendo já um relacionamento mais íntimo. E orientá-la no sentido de usar preservativo [...]. Isso se, tanto faz se é menino ou menina. Agora não me pergunte o que eu faria com a menina. Porque eu não sei qual seria a reação da garota. 0 h, engraçado, eu associei a Aids a um menino. (Escola de ensino fundamental, zona leste)

\section{Conflito entre alunos "normais" $e$ "órfãos por Aids"}

Interações entre alunos "normais" e órfãos por Aids que resultaram em conflito foram interpretadas pelos educadores pelo fato de terem HIV, serem provenientes de "famílias desestruturadas" e pobres. Também foi sugerido que tais aspectos levariam esses alunos a nutrir um sentimento de revolta.

A ausência de uma família nuclear, especialmente de uma família que possa prover 
apoio material, dificultou a compreensão do educador acerca de seus alunos, sendo utilizada como preditora de alguns comportamentos tidos como indesejáveis dos alunos órfãos (que, por sua vez, apresentariam uma dinâmica psíquica própria), conforme os dois próximos relatos da mesma depoente:

A gente se preocupa pela adolescência deles [...] essa orientação sexual, essa orientação comportamental [...]. Quando você vive numa família, você [referindo-se ao papel do educador] chama o pai ou a mãe [...], você percebe como que é a constelação familiar, como é que é o relacionamento das pessoas e, num grupo assim maior [referindo-se a jovens em casa de apoio], onde existem muito, muitos voluntários também. Às vezes, você não pode perceber que tipo de relações sociais, humanas, a interação... do comportamento deles, entre eles, como é que ocorre. (Escola de ensino fundamental e médio, zona norte) Eles vêm de um ambiente diferente, eles vão encontrar aqui, nos coleguinhas deles, tudo que eles não têm. Porque aqui eles vão encontrar crianças saudáveis, criança que tem, primeiramente, a primeira coisa, saúde, em segundo lugar, uma família [...] e classe média pra cima [...]. Então, crianças que têm bens materiais e que têm bens emocionais também, que e a convivência com a família, com os irmãos e tudo mais. Então é muito comum, às vezes, a criança até apresentar uma certa revolta. E como é que a criança se revolta? A criança, às vezes, se revolta brigando, outras vezes pegando as coisas do outro. (Escola de ensino fundamental e médio, zona norte)

Duas coordenadoras relataram conflitos nos quais os alunos manipularam o seu próprio estigma:

0 preconceito, às vezes, tá na própria pessoa [...]. Uma vez o F., sabe o que o F. fez? Ele tava ameaçando todo mundo com alfinete na mão e ele dizia assim: "Olha, o meu sangue é ruim, hein! Eu vou cutucar e vou pôr em todos vocês!" [...] Eu não sei se ele queria jogar e ninguém queria que ele jogasse, alguma coisa assim... (Escola de ensino fundamental e médio, zona norte)

"É, vocês ficam, vocês sabem que eu tenho, que eu tenho Aids"... E eu senti isso como uma intimidação para as outras pessoas [...]. Eu acho que até por motivo de falar: "olha, eu posso transmitir uma coisa ruim pra você" [...] ela tinha muitos problemas de indisciplina... (Escola de ensino fundamental, zona norte)

\section{Dificuldades de aprendizagem e HIV}

Uma coordenadora atribuiu as dificuldades de aprendizagem de alunos órfãos e soropositivos aos efeitos colaterais da medicação antirretroviral e a problemas emocionais desses alunos.

Na questão da aprendizagem, ainda não tá provado e tudo mais, os médicos dizem que não, mas nós professores sentimos que há uma dificuldade. Eu não sei dizer bem pra você se é mais o problema emocional ou, mas eu acredito que seja também por causa dos remédios que eles tomam [...], tem outros que são esforçados, que fazem questão de aprender, que querem aprender, e a gente percebe que tem uma dificuldade até cognitiva. (Escola de ensino fundamental e médio, zona norte)

\section{Revelação da orfandade por Aids: estigma sentido e vivido}

0 relato seguinte descreve uma revelação da orfandade por Aids que resultou em discriminação por parte de colegas:

Ela sofreu muito com a morte da mãe por saber que tinha Aids, ela sofreu algumas discriminações de amigos, de amigas quando ficou sabendo. (Escola ensino infantil, zona oeste)

No relato a seguir, o direito à privacidade da criança foi violado quando a comunidade escolar soube que seus pais haviam falecido em 
decorrência da Aids. A idade da criança também foi apontada como fator de maior suscetibilidade à discriminação:

Um outro fato que eu observei foi que a Maria tava dando aula, a professora Flávia e alguns alunos quiseram saber, conhecer também, lá dentro da sala, quem era o tal do Rubens. E a Maria teve que falar quem era, sem apontar. Então esse tipo de discriminação bem assim sutil. Sutil que se talvez fosse uma pessoa já adulta, alguma coisa assim que se tivesse um linguajar, e até pudesse ta discutindo, batendo boca, saindo no tapa. Que não era o caso do Rubens, que ele era criança. (Escola de ensino fundamental, zona oeste)

Não revelar a orfandade por Aids também foi indicado como repercussão do estigma da Aids, especialmente se a criança em questão for soropositiva. Ao ser indagada sobre a presença de alunos órfãos por Aids na escola, uma diretora comentou:

Ninguém nunca veio falar disso comigo [...] nenhum aluno, nenhum pai, nenhum professor. E fica a dúvida “será que não tem nenhuma criança com isso, nenhum jovem? Ou não sabe?". Olha que são cinco anos na direção, e tudo passa pelo diretor [...] Eu acho que [...] por preconceito, por medo do preconceito. Do medo do preconceito. (Escola de ensino fundamental, zona oeste)

Inicialmente, um coordenador não via problemas na revelação da orfandade por Aids de uma criança soronegativa. No entanto, ao ser solicitado que imaginasse a mesma criança com HIV, o entrevistado apresentou outra situação:

A Márcia tendo HVI... Ela não, ninguém sabia também, na escola. Ela não contava [referindo-se à orfandade por Aids]. Assim, as coisas acontecem na escola sem a gente saber. Principalmente Aids [...] as pessoas sabem que têm e têm medo de falar até por causa do prejuízo, pré-julgamento, aquelas coisas todas de serem excluídas. Já são. Por natureza já são. (Escola de ensino fundamental, zona oeste)

\section{Contato físico entre profissionais e alunos com HIV}

Embora não explicitamente, profissionais de educação teriam receio de se infectarem com HIV no contato físico com alunos órfãos por Aids soropositivos, conforme relatos de uma diretora e um coordenador.

Eu nunca vi [referindo-se à criança ter sofrido alguma restrição]. Eu não presenciei, mas eu acho que... inconscientemente tinha. [...] Eu acho que na... na questão dos cuidados com a Maria, mesmo. Se a Maria se machucasse, eu não sei se as pessoas não teriam... pode ser que tenha uma pessoa que viria prontamente ajudá-la, mas que as pessoas iam ficar assustada... (Escola de ensino fundamental, zona oeste)

0 fato de ter um aluno com Aids, pra todos, é ainda um tumulto pra alguns professores. Mas mesmo que eles demonstrem que não, que eles já conhecem tudo, eles falam muito assim. 0 tormento seria disso, ta pegando, "ah, fulano de tal tá com Aids, não sei o quê, cuidado com o sangue, não sei o quê". Eles fazem mais isso. (Escola de ensino fundamental, zona oeste)

\section{Reforçadores do estigma da Aids: homofobia e racismo}

Um coordenador relatou como o racismo e o preconceito contra homossexuais reforçam a discriminação por Aids na escola.

É bem assim: a questão do negro ainda não é resolvida no Brasil, nas escolas principalmente. [...] Agora, além de ser negro e ter o vírus da Aids, já é uma coisa bastante grave pros ouvidos conservadores que nós temos. [...] 
Por exemplo, a Aids sempre é associada ao fato da pessoa ser homossexual. 0 negro já é discriminado, o homossexual também. Então, você vê a carga que é além de ser negro e ser homossexual seria mais... Discriminados. Agora você pergunta assim: "se fosse negro?". Com certeza seria bem discriminado. (Escola de ensino fundamental, zona oeste)

\section{Respostas institucionais ao estigma da Aids e prevenção às DST/Aids}

Quando cientes da possibilidade de que o aluno venha a sofrer algum tipo de discriminação por parte da comunidade escolar, os educadores relataram o que fizeram/fariam para evitar que isso acontecesse. Os relatos foram organizados de acordo com três tipos de respostas: 1) ações dirigidas aos alunos afetados pela Aids; 2) ações dirigidas aos alunos não-afetados pela Aids e 3) ações destinadas ao debate sobre estigma e discriminação na escola.

Nas ações dirigidas aos alunos afetados pela Aids, uma das alternativas foi não revelar a condição de orfandade ou sorologia a qualquer pessoa da comunidade escolar, conforme relato de uma coordenadora:

Chegou pra conversar que ela tinha esse problema [referindo-se a uma aluna de 11 anos, órfã por Aids e soropositiva] e eu fiquei preocupada de momento como seria a reação dos professores sabendo e de outros alunos, porque eu me coloquei no lugar dela e me senti rejeitada. [...] Mas eu não cheguei a comentar com os professores. [...] Se ficar isso a nível de conhecimento mais público, ela vai ter que acabar não estudando.(Escola de ensino fundamental, zona norte)

Atividades de prevenção às DST/Aids realizadas na década de 90 foram indicadas como importantes marcadores para a conscientização da comunidade escolar. No entanto, a não discriminação não deixou de ocorrer, necessariamente, por recusa ao estigma, tratando-se ocasional- mente de um dever profissional e legal, conforme os dois próximos relatos de um coordenador:

Tem se feito tanto, tanto. Eu lembro que no estado mesmo. Depois disso, no ano de 96, 96, teve uma campanha muito boa de DST/ Aids [...] acho que todos os professores foram obrigados a participar do, do envolvimento. E não é por querer, é por obrigação da profissão. E acho que a partir daquele momento [...] houve uma mudança, eu acho, no comportamento... Não que aceitasse. Mas que, pelo menos, não tivesse um pré-julgamento ou excluísse alguém de, o povo que tem isso. Mas as pessoas ainda são, não sei, por natureza são excludentes. (Escola de ensino fundamental, zona oeste)

Em off, os professores encontram no corredor, eles têm receios, ainda há receios. Eles podem até se mostrarem receptivos, dizer que a gente vai ta respeitando porque professor é funcionário. Eu acredito que não [referindo-se à não discriminação] até porque eles sabem das consequências de preconceito, tá na constituição a questão. (Escola de ensino fundamental, zona oeste)

A dificuldade de abordar temas sobre prevenção de DST/Aids foi atribuída a uma indissociabilidade entre expor situações aos alunos com a finalidade de esclarecê-los sobre algum assunto e, consequentemente, estimular entre eles comportamentos tidos como indesejáveis. A reação negativa de pais de alunos também foi apontada como uma dificuldade para atividades de prevenção. Ao afırmar que a informação sobre prevenção seria uma forma de combater o estigma da Aids, um coordenador descreveu no que consistiria a prevenção e quais seriam os desafios da escola:

Entrevistador: Para prevenção, o que é importante?

Coordenador: 0 conhecimento da situação, o conhecimento de como é que se pega, transmissão [...]. Esclarecimento quanto ao uso de dro- 
gas, ao não uso, mas, na verdade, o adolescente, se a gente vai esclarecer, torna-se um foco de atenção e eles vão querer experimentar [...]. Por exemplo, alguém que usa, que bebe bastante, deixou de beber, vai dar palestra, vai incitar os alunos a beber [...]. Então é muito complicado esse negócio. [...] Na escola, tem que trabalhar com esclarecimento. [...] Mas é muito difícil; por exemplo, no ano passado aqui teve uma professora que queria fazer isso. Você não imagina, os pais caíram matando nessa professora. (Escola de ensino fundamental, zona oeste)

Por fım, além da menção à necessidade de informação sobre a transmissão do HIV, houve um relato de um coordenador sobre uma resposta institucional dirigida ao debate sobre estigma e discriminação:

Quando você fala da questão do estigma... Como fazer pra acabar com ele? É difícil. 0 que a escola pode fazer é provocar entre todos um sentimento de... [...] sentir na pele a coisa e ta enviando esforço, esforços pra ta sanando a coisa. E como sanar? Seria mais com publicidade mesmo. [...] Dizer os prós e os contras de se contrair Aids. E como se contrai, como se prevenir e assim por diante. Acho que a escola não pode fazer mais do que isso [...]. Porque eu acho tão difícil essa questão de, do preconceito... [...] "ah, se ele é viado ele tem Aids...” [...] E é bem assim, tirar essa cultura machista ainda. Ah, demora muito pra chegar ao patamar da igualdade de fato. A igualdade de fato que os negros, coitados, eles estão... Eu tenho dois sobrinhos que eles são filhos de negros. É como fossem meus filhos, gosto muito deles. Mas até a gente, a gente ainda às vezes se pega no preconceito, inconsciente, involuntariamente. (Escola de ensino fundamental, zona oeste)

\section{Discussão}

Os relatos de estigma indicam restrições no ambiente escolar que se tornam obstáculos para o exercício do direito à educação, bem como para a sociabilidade e vida afetiva e sexual dos alunos órfãos.

Os episódios descritos no presente estudo diferem daqueles encontrados na literatura sobre estigma da Aids e educação. As primeiras respostas de estigma na escola foram principalmente marcadas pelo obstáculo no acesso à escola, por exemplo, pela dificuldade do responsável por uma criança soropositiva matriculá-la na escola.

Embora não tenha sido registrada nenhuma restrição quanto ao acesso, os relatos apontam restrições no ambiente escolar com base no estigma da Aids. Persistem algumas metáforas da Aids para a geração seguinte (vide os relatos sobre os meninos revoltados e perigosos que manipulam o estigma da Aids para obter algo em seu favor, sem nenhuma empatia por seu sofrimento) e reaparecem associadas à afetividade e sexualidade quando esses alunos entram na adolescência.

Portanto, podemos dizer que, atualmente, será menos provável encontrar uma escola que recuse a matrícula de uma criança com base no seu estado sorológico HIV positivo. Parece haver consenso nos relatos do presente estudo de que crianças com HIV devam frequentar a escola, não havendo mais manifestações explícitas de que elas representariam um perigo aos alunos tidos como saudáveis. Entretanto, esses mesmos educadores podem se ver no direito e dever de intervir no namoro de um jovem casal de alunos sorodiscordante, sugerindo claramente o rompimento desta relação. 0 fator crucial para o aluno sofrer estigma na escola é ter HIV: ocorre uma racionalidade sobre a transmissão do HIV, que tolera o "estar perto de" (diferentemente do início da epidemia), mas não aceita a experiência da sexualidade de um jovem portador.

\section{Tensão permanente entre normais e estigmatizados}

Os relatos do presente estudo expressam a tensão dos "contatos mistos”. Nestas situações de interação social compartilhadas por normais e estigmatizados, os indivíduos que possuem 
um estigma aceito oferecem um modelo de normalização, indicando o limite das condutas dos normais quando se relacionam com o estigmatizado como se ele fosse um igual (Goffman, 1978). Isso pode ser observado pelo fato de um aluno soropositivo e órfão por Aids ser concebido como normal (porém nunca, de fato, igual) pelos educadores até o momento em que ele começa a namorar, desentende-se com outros colegas ou apresenta dificuldades de aprendizagem. Outro aspecto observado foi o recurso dos "desacreditáveis" - alunos órfãos e suas famílias - ao acobertamento do estigma por meio do controle da informação, ou seja, a decisão de não revelar a condição de orfandade por Aids na escola por temer a discriminação.

Quanto à associação que uma educadora faz entre soropositividade e dificuldade de aprendizagem, Goffman (1978) observa que temos uma tendência a inferir uma série de imperfeições a partir de uma imperfeição original. Diante de alguém com deficiência visual, é comum que as pessoas se dirijam a esta falando mais alto ou segurando seu braço, inferindo que alguém com deficiência visual deve ter também outras dificuldades (auditiva, motora, entre outras) (Goffman, 1978). No presente estudo, a soropositividade, originalmente uma referência para a descrição do quadro geral de saúde da criança, passa a ser utilizada como explicação de dificuldades de aprendizagem.

Observamos também, nos relatos, a transição entre estereótipo e estigma. Goffman (1978) compreende estigma como "um tipo especial de relação entre atributo e estereótipo". Entendemos por estereótipo uma generalização cultural e normativa com três características centrais: abusivo (atinge uniformemente todos os membros de um grupo), extremo (conotação superlativa) e frequentemente mais negativo do que positivo (Lima, 1997). No caso do estereótipo do gênero masculino, há a representação de que meninos possuem natureza sexual mais acentuada e menor responsabilidade; isso é o que se espera deles (portanto, não constitui estigma porque confirma o estereótipo). Quan- do soropositivos (atributo), eles passam a ser desacreditados (ou objetos de estigma) porque, dada a sua natureza mais sexual e de caráter menos responsável, eles transmitirão o HIV a outras pessoas sem a menor preocupação. Consequentemente, esses meninos passam a ser designados como perigosos pelos normais, que passam a se relacionar com eles por meio deste último sentido atribuído.

\section{Explicação sobre os problemas dos alunos órfãos por Aids}

A explicação de educadores sobre o comportamento de alunos tidos como revoltados/ indisciplinados como produto do modelo de organização familiar não ocorre somente no que diz respeito a crianças afetadas pela Aids. Outros aspectos, tais como consumo de drogas, gravidez precoce na adolescência e agressividade, são majoritariamente atribuídos à família dos alunos, culpabilizando ambos (Patto, 2002). Em revisão de literatura, Angelucci et al. (2004) caracterizaram quatro tipos de explicação do fracasso escolar na literatura, a saber: 1) problema psíquico (culpabilização da criança e da família); 2) problema técnico (culpabilização do professor); 3) problema institucional (a lógica excludente da educação escolar) e 4) problema político (cultura escolar, cultura popular e relações de poder). No presente estudo, o discurso sobre a família desestruturada preditora de comportamentos inadequados, a proibição do namoro e as explicações do baixo desempenho escolar e da indisciplina expressam um forte caráter "psicologizante" (ou seja, a explicação destes fenômenos está no indivíduo ou em sua família), em que o educador assume como papel disciplinar a vida afetiva e sexual dos alunos afetados pela Aids.

Dessa forma, não houve relatos que implicassem a própria instituição escolar, bem como as pessoas que compõem a comunidade escolar, como também reprodutora do baixo desempenho escolar, da indisciplina e de outras formas de estigma. Considerando a estigmati- 
zação como um processo socialmente construído de desvalorização do indivíduo, a escola é um espaço potencial tanto para a perpetuação quanto para a construção de ações dirigidas à mitigação do estigma. Nesse sentido, assim como Angelucci et at. (2004) concebem o fracasso escolar, entendemos que o estigma da Aids é, sobretudo, um problema político.

Portanto, se a escola optar por abordar a temática da Aids somente no que diz respeito a evitar a infecção pelo HIV (recorrendo aos especialistas em DST/Aids), ficam excluídas as dimensões vividas por aqueles já afetados (portadores e órfãos) como, por exemplo, o estigma da Aids. Em outras palavras, desaparecem do cenário escolar os que vivem ou convivem com o HIV/Aids.

A desinformação é, sem dúvida, um importante ingrediente do preconceito, mas se este não for considerado em sua complexidade, examinando-se as relações políticas de poder e dominação, continuaremos tratando esta questão como mera necessidade de "tolerância cultural" ${ }^{11}$. No caso do estigma da Aids, nos contentaríamos com a garantia de proteção do direito à não discriminação, sem que pudéssemos entender como a somatória de estigmas relacionados a gênero, sexualidade, uso de drogas, raça/ etnia e classe social pôde produzir respostas tão explosivas de raiva, medo, negação, exclusão, dentre muitas outras. Portanto, a informação deve vir juntamente com a explicitação do contexto que a faz necessária, possibilitando a reflexão. Paulo Freire (1996) lembra-nos que não há prática pedagógico-progressista possível somente com ciência e técnica; há virtudes indispensáveis ao educador, como a aceitação e o respeito às diferenças, abertura à justiça, recusa aos fatalismos e tantas outras.

\section{Alunos ainda pouco visíveis}

É possível que a pouca visibilidade que a DST/Aids teve para a maioria dos educadores no presente estudo expresse uma crença difundida de que a Aids "já passou, pois pouco se ouve falar dela", fazendo com que o assunto caia no esquecimento. Contudo, isso não anula, evidentemente, o cotidiano de crianças e jovens que sentem e vivem o estigma da Aids, que se ocupam com a revelação, namoro, planos de vida desnecessariamente restritos etc. (Ayres et al., 2006).

Em estudo qualitativo realizado na África do Sul, Witt e Lessing (2005) relatam que os educadores consideram que os órfãos por Aids sofrem mais com a falta de recursos materiais após a perda dos pais e também necessitam de segurança, aceitação e serviços de suporte psicológico para lidar com estresse e medos. Ainda, estes alunos manifestam problemas emocionais, sendo os principais a depressão, a tristeza e a estigmatização. Talvez pelo fato de a Aids no Brasil não ter a mesma proporção epidêmica que na África do Sul, a questão da orfandade por Aids ainda seja pouco visivel na comunidade escolar, possivelmente ocultando que os alunos órfãos enfrentam situações semelhantes às descritas pelo estudo citado. Outra pesquisa na Escócia aponta o quanto crianças e jovens afetados pela Aids desejam ter melhor suporte e compreensão na escola, ter informação e discutir abertamente sobre o HIV em suas vidas (Tisdall et al., 2004).

Relatos como "fez-se tanto em 96", o desconhecimento acerca da transmissão do vírus expresso pelo medo de professores de se infectarem com HIV no contato com alunos ou o medo de que alunos soronegativos (classificados como "normais") contraiam HIV ao namorar alunos soropositivos indicam o quanto a prevenção às DST/Aids está longe da realidade do cotidiano das escolas estudadas. Consequentemente, ações para mitigar o estigma da Aids e sua potencial discriminação nem ocorrem à comunidade escolar. Em outras palavras, desaparecem do cenário escolar os que vivem ou convivem com HIV/Aids.

É importante observar que as respostas institucionais, na escola, dirigidas a crianças e

11. Observação feita pelo prof. José Moura Gonçalves Filho durante a disciplina de pós-graduação "Humilhação social: alguns elementos para 0 exame psicológico de um sofrimento político", em 16/08/2006, no Instituto de Psicologia, Universidade de São Paulo. 
jovens que convivem com a Aids (soropositivas ou não para o HIV) se concentram na proteção contra a discriminação, especificamente para evitar a segregação baseada no medo da infecção por HIV ou que os alunos sejam explicitamente ofendidos (por exemplo, por xingamentos). Entretanto, alternativas indicadas pelos entrevistados, tais como a necessidade de atividades de prevenção e debate sobre preconceito, não tiveram como destinatário precisamente os alunos órfãos por Aids. Em outras palavras, é como se a prevenção e o debate sobre estigma fossem prerrogativas do polo negativo da epidemia, e ao polo positivo estivesse reservada tão somente a proteção contra a discriminação.

Por fim, os relatos indicam o quanto o estigma e a discriminação relacionados ao HIV/ Aids podem aprofundar uma desigualdade social já instalada no âmbito da educação, constituindo obstáculos ao direito à educação, à convivência familiar, ao lazer, à privacidade, ao sigilo/confidencialidade e à vida afetiva dos jovens.

Apresentamos no Quadro anexo uma sintese das circunstâncias de ocorrência de estigma, os elementos do processo de estigmatização nas situações do cotidiano escolar e os respectivos direitos e princípios afetados conforme estabelecidos pela "Convenção sobre os Direitos da Criança"12.

\section{Recurso metodológico a diversos contrastes sociais}

0 recurso aos contrastes (soropositividade, tipo de orfandade, institucionalização, raça/ etnia, gênero e idade) permitiu respostas mais espontâneas, minimizando discursos "politicamente corretos" e garantindo a adequação da técnica de obtenção dos dados. Solicitar aos entrevistados que imaginassem o aluno órfão em questão com outras características (por exemplo, se a criança fosse negra, se fosse um menino em vez de uma menina, se a criança tivesse HIV, se fosse um adolescente em vez de uma criança) permitiu vislumbrar situações diferentes, inclusive discriminações.
A utilização desses contrastes exprime a ideia de que há diferenças que podem vir a constituir desvios, resultando em tratamento desigual. Na experiência do estigma da Aids vivido por crianças e jovens, infectados ou afetados, sabemos que estas condições (soropositividade, tipo de orfandade etc.) configuram expectativas normativas em relação a esses indivíduos. Nas palavras de Goffman (1978), essas exigências que fazemos correspondem a uma identidade social virtual, em que as características atribuídas ao indivíduo ocorrem por um retrospecto em potencial. 0 estigma e a discriminação decorrentes aprofundam a discrepância entre esta identidade social virtual e a identidade social real, ou seja, a categoria e os atributos que o sujeito, efetivamente, prova possuir. Com o recurso dos contrastes, podemos observar que ser negro é considerado uma condição que pode fazer com que um aluno órfão por Aids sofra mais estigma.

\section{Considerações finais}

É necessário cuidado para não inverter a lógica da responsabilização sobre o estigma da Aids: não se pode culpabilizar o educador, tal como acontece com alunos e suas famílias. Admitir os próprios preconceitos constitui uma tarefa árdua a todos, especialmente àqueles incumbidos da formação de outrem. Rubem Alves (2001) comenta:

Jaspersen observou, certa vez, que "os homens cantaram suas emoções antes de enunciar suas idéias". Mas existe também a situação inversa: a de enunciar idéias mesmo depois que delas fugiram o amor e o desejo - sonambulismo, ventriloquia. Não será essa a nossa situação?

E eu pensaria que o acordar mágico do educador tem então de passar por um ato de regeneração do nosso discurso. [...] A formação do educador? Antes de mais nada: é necessário reaprender a falar. (p. 34)

12. Adotada na Assembleia Geral das Nações Unidas em 20 de novembro de 1989. Disponível em: <http://www.unicef.org.br>. Acesso em: 15 set. 2010] 
Isso pode auxiliar a compreensão do quão é difícil desconstruir discursos "politicamente corretos”. Estes não comportam os afetos necessários ao combate ao estigma e à discriminação, pois o preconceito é abordado a partir de um discurso ético distanciado da vida cotidiana e mediado por racionalizações. Embora necessária, a racionalização nunca será suficiente para ressignificar valores. Atualmente, parece-nos que há uma imposição tácita de "exaltação" aos direitos humanos, ao ECA, à igualdade racial, entre outros, no discurso dos educadores, que, por sua vez, não encontram espaço para falar abertamente sobre suas próprias experiências de preconceito. Assim, não há possibilidade de "humanizar" o preconceito, ou seja, de assumilo como sendo comum a todos, uma vez que constitui parte do processo de socialização. Portanto, é necessária a construção de práticas educativas (tecnologias) que possam fazer mediações na linguagem para expressar o estigma.

As estratégias de prevenção não podem ser restritas à transmissão de informações ou pressupor polos positivo/negativo quanto à possibilidade de infecção para o HIV; são práticas reflexivas que requerem o exercício da autonomia.

Estratégias de prevenção às DST/HIV/Aids devem superar o plano das práticas de proteção individual. A prevenção baseada na autonomia compreende os jovens como capazes de serem sujeitos das decisões sobre sua própria saúde, bem como fortalece os direitos afirmados (Paiva; Pupo; Barboza, 2006), como a garantia de acesso à escola e do sigilo da condição sorológica de pessoas vivendo com HIV. Trazer a Aids de volta ao cenário escolar não implica expor ou revelar pessoas na comunidade escolar que vivam ou convivam com o HIV, e sim afirmar a prevenção como direito (Paiva; Pupo; Barboza, 2006).

Contudo, uma vez que os profissionais de educação venham a ter conhecimento da presença de alunos órfãos por Aids, indicamos dois níveis de intervenção na escola que podem fortalecer a proteção contra o estigma e a discriminação relacionados à Aids: 1) o desenvolvimento de habilidades que informarão a autoproteção e, eventualmente, o cuidado com a infecção pessoal e da família; 2) assistir na reorganização da vida destes alunos após a perda dos pais, fortalecendo a afirmação de seus direitos individuais (Kelly, 2000).

É imprescindivel que haja articulação entre os setores da educação e da saúde. Os programas municipais e estaduais de prevenção às DST/Aids podem contribuir para o desenvolvimento de projetos de prevenção, mapeando e fornecendo os recursos necessários junto à comunidade escolar de modo que fomente a sustentabilidade de ações locais.

Estratégias de prevenção às DST/Aids devem também incluir a mitigação do estigma da Aids como finalidade dos Temas Transversais dos Parâmetros Curriculares Nacionais (PCNs), ao problematizar valores gerais e unificadores da escola em relação "à dignidade da pessoa, à igualdade de direitos, à participação e à coresponsabilidade de trabalhar pela efetivação do direito de todos à cidadania” (Brasil, 1998). Na relação entre Aids e educação, os temas sobre ética, saúde, pluralidade cultural e orientação sexual exprimem três ideias centrais para o combate ao estigma da Aids: o respeito à diferença só é possível mediante justiça, diálogo e solidariedade; a consciência de que a saúde expressa a interação entre homens e suas condições de vida; e a sexualidade como produção histórica e cultural.

Na direção contrária às conquistas do Programa Nacional de DST/Aids quanto à expansão da cobertura do tratamento antirretroviral para as pessoas que vivem com HIV/Aids e de acordo com as críticas quanto à deficiência de uma efetiva resposta de prevenção no campo da Aids entre a população jovem, os episódios de estigma da Aids descritos no presente estudo expressam a ausência de atividades de prevenção de DST/ Aids que incluam os que convivem com HIV/ Aids e do debate sobre estigma e discriminação nas escolas visitadas, e também remetem à difıculdade da comunidade escolar em problematizar outras modalidades de estigma ligados a raça/ etnia, gênero, pobreza e organização familiar. 
Quadro: Síntese das circunstâncias de ocorrência de estigma, elementos do processo de estigmatização e direitos e princípios afetados.

\begin{tabular}{|l|l|l|l|}
\hline & Circunstâncias & Elementos do processo de estigmatização & Direitos/princípios afetados \\
\hline $\mathbf{1}$ & $\begin{array}{l}\text { Namoro e } \\
\text { sexualidade } \\
\text { sorodiscordante; interferência da escola tem por finalidade a } \\
\text { interdição do relacionamento; jovens com HIV não devem ter } \\
\text { filhos para não transmitir o vírus; na cultura sexista, meninos são } \\
\text { incentivados a serem mais "sexuais" e não terão cuidados para } \\
\text { autoproteção e dos parceiros (particularmente os meninos com } \\
\text { HIV). }\end{array}$ & $\begin{array}{l}\text { Sexuais e reprodutivos; não } \\
\text { discriminação; prevenção; } \\
\text { sobrevivência e desenvolvimento; } \\
\text { participação }\end{array}$ \\
\hline $\mathbf{2}$ & $\begin{array}{l}\text { Conflito entre alunos } \\
\text { normais e órfãos por } \\
\text { Aids }\end{array}$ & $\begin{array}{l}\text { Conflitos ocorrem porque alunos órfãos são provenientes de } \\
\text { famílias pobres e "desestruturadas"; órfãos por Aids teriam um } \\
\text { psiquismo característico, marcado pelo sentimento de revolta. }\end{array}$ & Não discriminação \\
\hline $\mathbf{3}$ & $\begin{array}{l}\text { Dificuldade de } \\
\text { aprendizagem }\end{array}$ & $\begin{array}{l}\text { Aluno órfão por Aids com HIV tem dificuldade em razão de seu } \\
\text { "problema emocional" e dos efeitos dos antirretrovirais. }\end{array}$ & Não discriminação \\
\hline $\mathbf{4}$ & $\begin{array}{l}\text { Revelação da } \\
\text { orfandade por Aids } \\
\text { Crianças que sofreram/sofreriam discriminação na comunidade } \\
\text { escolar quando souberam/caso soubessem sobre a orfandade; } \\
\text { famílias mantêm orfandade por Aids em segredo em virtude do } \\
\text { medo do estigma. }\end{array}$ & Não discriminação e interesse \\
superior da criança
\end{tabular}

\section{Referências bibliográficas}

ALVES, R. Conversas com quem gosta de ensinar. São Paulo: Papirus, 2001.

ANGELUCCI, C. B. et al. 0 estado da arte da pesquisa sobre o fracasso escolar (1991-2002): um estudo introdutório. Educação e Pesquisa, São Paulo, v. 30, n. 1, p. 51-72, jan./abr. 2004.

ASSOCIAÇÃO BRASILEIRA INTERDISCIPLINAR DE AIDS (ABIA). AIDS e a escola: nem indiferença, nem discriminação. Rio de Janeiro, 1993.

AYRES, J. R. C. M. et al. Vulnerability, human rights and comprehensive health care needs of young people living with HIV/AIDS. American Journal of Public Health, Washington, v. 96, n. 6, p. 1001-1006, jun. 2006.

BOLETIM EPIDEMIOLÓGICO DE AIDS, HIV/DST E HEPATITES B E C DO MUNICÍPIO DE SÃO PAULO. São Paulo: Covisa, ano XIII, n. 12, jun. 2009.

BRASIL. Ministério da Educação e do Desporto. Secretaria de Educação Fundamental. Parâmetros curriculares nacionais: terceiro e quarto ciclos do Ensino Fundamental: introdução aos Parâmetros Curriculares Nacionais. Brasília, 1998.

DORING, M. Situação dos órfãos em decorrência da AIDS em Porto Alegre/RS e fatores associados à institucionalização. 2005, 98p. Tese (Doutorado em Saúde Pública)- Faculdade de Saúde Pública, Universidade de São Paulo. São Paulo, 2005.

FRANÇA-JUNIOR, I., DORING, M., STELLA, I. M. Crianças órfãs e vulneráveis pelo HIV no Brasil: onde estamos e para onde vamos? Revista de Saúde Pública, São Paulo, v. 40, n. supl., p. 23-30, 2006.

FREIRE, P. Pedagogia da autonomia: saberes necessários à prática educativa. São Paulo: Paz e Terra, 1996.

GOFFMAN, E. Estigma: notas sobre a manipulação da identidade deteriorada. Rio de Janeiro: Zahar, 1978.

KELLY, M. J. What HIV/AIDS can do to education, and what education can do to HIV/AIDS. In: ALL SUB-SAHARAN AFRICA CONFERENCE ON EDUCATION FOR ALL. Proceedings... Johannesburg, 2000.

KROKOSCZ, M. AIDS na escola: representações docentes sobre o cotidiano dos alunos e alunas soropositivos. 2005. 190p. Dissertação (Mestrado em Educação)- Faculdade de Educação, Universidade de São Paulo. São Paulo, 2005.

LIMA, M. M. Considerações em torno do conceito de estereótipo: uma dupla abordagem. Revista da Universidade de AveiroLetras, Aveiro, v. 14, p. 169-181, 1997. 
MALUWA, M.; AGGLETON, P.; PARKER, R. HIV and AIDS-related stigma, discrimination and human rights: a critical overview. Health and Human Rights, Boston, v. 6, n. 1, p. 1-15, 2002.

MANN, J. M.; TARANTOLA, D. J. M.; NETTER T. W. (Orgs.). AIDS in the world: the global AIDS policy coalition. Cambridge/London: Harvard University Press, 1992.

PAIVA, V.; PUPO, L.; BARBOZA, R. 0 direito à prevenção e os desafios da redução da vulnerabilidade ao HIV no Brasil. Revista de Saúde Pública, São Paulo, v. 40, n. supl., p. 109-119, 2006.

PARKER, R., AGGLETTON, P. Estigma, discriminação e AIDS. Cidadania e Direitos, Rio de Janeiro, n. 1, 2001.

PATTO, M. H. S. A produção do fracasso escolar. histórias de submissão e rebeldia. São Paulo: Casa do Psicólogo, 2002.

TISDALL, A. K. M. et al. Children in Need? Listening to children whose parent or carer is HIV positive. British Journal of Social Work, Oxford, v. 34, n. 8, p. 1097-1113, 2004.

WITT, M. W., LESSING, A. C. Educators' views on the needs and support of HIV/AIDS orphans in their psychosocial development. Journal of Child and Adolescent Mental Health, Grahamstown, v. 17, n. 1, p. 13-22, jan. 2005.

Recebido em 29.06.09

Aprovado em 31.05.10

Eliana Miura Zucchi é psicóloga e mestre em Saúde Pública pela Faculdade de Saúde Pública da Universidade de São Paulo (FSP/USP); Núcleo de Estudos para Prevenção da Aids (Nepaids) da USP. E-mail: elianamz@usp.br

Claudia Renata dos Santos Barros é educadora física e mestre em Saúde Pública, FSP/USP; Nepaids/USP.E-mail: claubarros@usp.br

Vera Silvia Facciolla Paiva é professora associada do Depto. de Psicologia Social e do Trabalho, Instituto de Psicologia/USP; Nepaids/USP. E-mail: veroca@usp.br

Ivan França Junior é professor doutor do Depto. de Saúde Materno-Infantil, FSP/USP; Nepaids/USP. 